\title{
Assessment of environmental conditions of Nan-Shih stream in Taiwan
}

\author{
Tung-Jer Hu ${ }^{a}$, Hsiao-Wen Wang ${ }^{\text {b,* }}$, Hong-Yuan Lee ${ }^{\mathrm{b}}$ \\ ${ }^{a}$ Department of Civil Engineering, Lanyang Institute of Technology, Yilan, Taiwan \\ ${ }^{\mathrm{b}}$ Department of Civil Engineering, National Taiwan University, Taipei, Taiwan
}

Received 10 December 2005; received in revised form 19 April 2006; accepted 19 April 2006

\begin{abstract}
Restoration is a complex endeavor requiring the understanding of the degrading environment before applying any improvement measure. Environmental and ecological data in Nan-Shih stream were investigated in this study to assess its stream condition. Based on the data collected, the Index of Biotic Integrity (IBI index) which takes fish species as the major target, the Family-level Biotic Index (FBI) aquatic insects Hilsenhoff index and the Genus Index (GI) of algae were thus analyzed to quantify Nan-Shih stream's ecological system. The indices above were then applied on Index of Stream Condition (ISC index) to describe the overall river condition. Modified sub-indices, including the hydrology, physical form, streamside zone, water quality, and aquatic life, were made and used to provide baseline assessment information. ISC value is 33.89 evaluated as marginal level, in which hydrology sub-index score was the lowest indicating impact of artificial structures affecting flow significantly. The recommendations of the river corridor restoration and the habitat improvement were thus proposed as a reference for river management.
\end{abstract}

(C) 2006 Elsevier Ltd. All rights reserved.

Keywords: Environmental indicators; Biotic integrity; Fish; Invertebrate; Algae; Restoration

\section{Introduction}

Restoration is a complex endeavor that begins by recognizing natural or human-induced disturbances that are damaging the structure and functions of the ecosystem or preventing its recovery to a sustainable condition. River restoration requires an understanding of the structure and functions of stream corridor

\footnotetext{
* Corresponding author.

E-mail address: d91521011@ntu.edu.tw (H.-W. Wang).
}

ecosystems and the physical, chemical, and biological processes that shape them (Stream Corridor Restoration, USDA, 2001).

For stream restoration, the Committee on Restoration of Aquatic Ecosystems (National Science Council, 1992) suggested that decreasing the stresses of stream and river can directly improve stream ecological environment and achieve the objective of stream rehabilitation. With characteristics of river continuum, stream ecosystems have diverse components and environments from upstream channel to 
estuarine area. Therefore, specific goals of any particular restoration and composition of conservative object should be well understood and defined within the context of the current conditions and disturbances in the stream before applying any improvement measure.

The subtle impact of some parameters is often difficult to assess from only measured chemical concentrations (La Point, 1995). While physicochemical parameters may predict potential aquatic degradation, they cannot always address the realized biological effects in the instream community. Instream response to stressors may not be readily apparent until some or all community components cycle through an impact. The direct measure of aquatic life communities has been cited as a more appropriate parameter because it integrates the responses from an organismal level (Cairns and van der Schalie, 1980; Cairns and Mount, 1990; Karr, 1991). At a minimum, a biological community sampling program is needed as a verification tool for assessment of aquatic life support in waters where causes, sources, and support/nonsupport cannot be adequately determined from chemical investigations (La Point, 1995).

One of the best assessments of stream or waterbody integrity is the examination of its biological inhabitants (Hoffman et al., 1995; Karr, 1991). Rapid Bioassessment Protocols (RBPs), developed by Barbour et al. (U.S. EPA, 1999), have greatly increased the assessment efficiency and effectiveness of these surveys. RBPs can reflect overall ecological integrity and directly assess the status of a waterbody when used with careful consideration of the system. Biological communities also integrate the effects of different stressors, providing an ecological measure of fluctuating environmental conditions.

Providing the scientific foundation for restoration can be accomplished by developing a suite of ecological indicators within a sound conceptual framework (Shen and Chen, 1998). An ecological indicator is an attribute of the system that can be measured and calculated to provide information about the health or integrity of that system in much the same way that the temperature of a patient provides a doctor with diagnostic information about the patient's overall health. Using a logical conceptual framework to develop the indicators is useful to assure that the suite of indicators can address the integrity of the system as an ecological whole, as well as each of the component parts.

In Taiwan, the attention for the research of using indicators to understand the environmental conditions and disturbances in the stream has been raised in recent years. Lai et al. (1994) described the composition and seasonal variations of planktonic and benthic biota as well as pollutants in San-Yeh-Kong river in Taiwan by using the ecological index. Hsu and Yang (1997) conducted investigations of aquatic insects in the Keelung river in Taiwan and assessed the water quality by using Hilsenhoff Biotic Index, Family-level Biotic Index, etc. Liang et al. (1997) applied Index of Biotic Integrity in north central Iowa streams for measuring environmental quality. Chu (2005) modified IBI to evaluate stream alteration and ecological impact on Hofangi stream and suggested the scoring criteria of a sound indicator should be developed to fit the environment in Taiwan. While most of the literature on environment evaluation in Taiwan treats only biological aspect, little information is available in the literature on the overall evaluation considering the integrity of the system as an ecological whole. The intention of this study was to introduce a sound conceptual framework of a suite of ecological indicators to fill the gap.

The main goal of this study was to determine the impact on the biota and habitat caused by degrading environment. Fish, benthic macroinvertebrates, and algae were selected as the biotic components for analysis. Assessments of the Index of Biotic Integrity (Karr, 1981, 1991), Family-level Biotic Index (FBI) aquatic insects Hilsenhoff index (Hilsenhoff, 1988) and the Genus Index (Wu, 1999; Wu and Kow, 2002) of algae was thus analyzed to quantify Nan-Shih stream's ecological system. The indices above were then applied on Index of Stream Condition (ISC index) (Ladson et al., 1999) to describe the overall river condition. Modified sub-indices were made and used to provide baseline assessment information relating instream community assessments. This incorporation presented as useful screening tools for the characterization and management.

By determining these responses, a better understanding of the state of Nan-Shih stream may be achieved. Suggestions of the river corridor restoration were thus proposed as a reference for river management. 

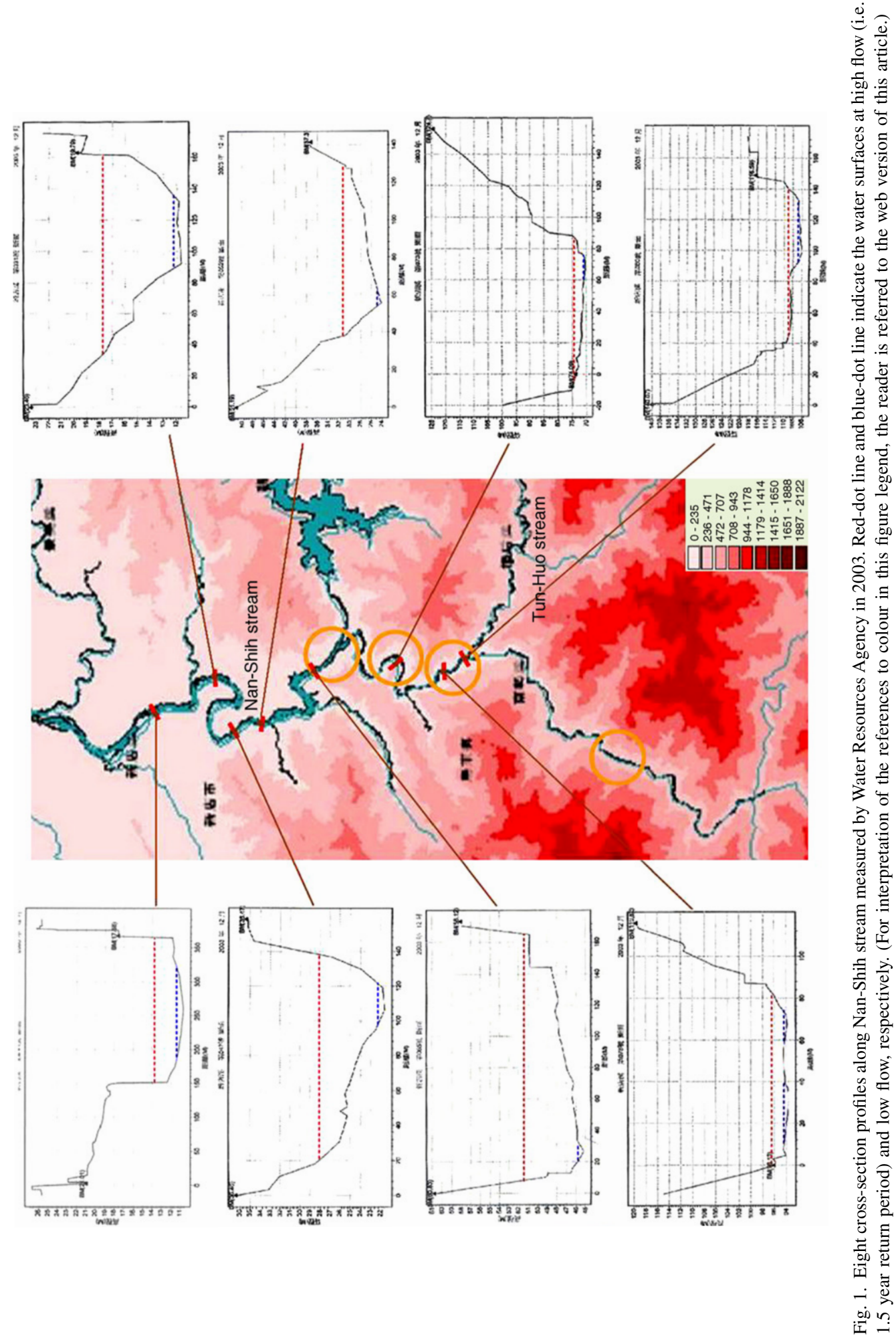


\section{Method}

\subsection{Study site}

Nan-Shih stream originates from Chi-Lan mountain (elevation is $2130 \mathrm{~m}$ ), sinuous flowing in the deep valley towards north. Tun-Huo stream and Bai-Shih stream are the tributaries of Nan-Shih stream which are converged from east at Wu-Lai and Kwei-Shan. The climate here is moderate and the annual average temperature is about $20{ }^{\circ} \mathrm{C}$. The average yearly rainfall is about $3250 \mathrm{~mm}$. Since the water amount in Nan-Shih stream is plentiful, it is an important source of water for downstream Taipei County and Taipei City. Hence, there are many hydraulic facilities along the streams. Fig. 1 shows eight cross-section profiles measured by Water Resources Agency in 2003.

\subsection{Field survey}

Field survey has been done at eight sites along NanShih stream. In this paper, four among a total of eight (Fig. 2) are selected to represent the evaluation results. Among these investigated sites, site 4 was chosen as the reference site based on the historical survey data and literature. The reference condition might be similar to what the stream corridor would have been like had it remained relatively stable. It might represent a condition less ideal than the pristine, but substantially improved form the present condition (USDA, 2001). Site 4 served as the reference site since its environment is most well-preserved and natural. Sampling was conducted four times (June, August, October, and December) in 2004. At each study site, field sampling procedures included an integrated assessment, which focused on the evaluation of

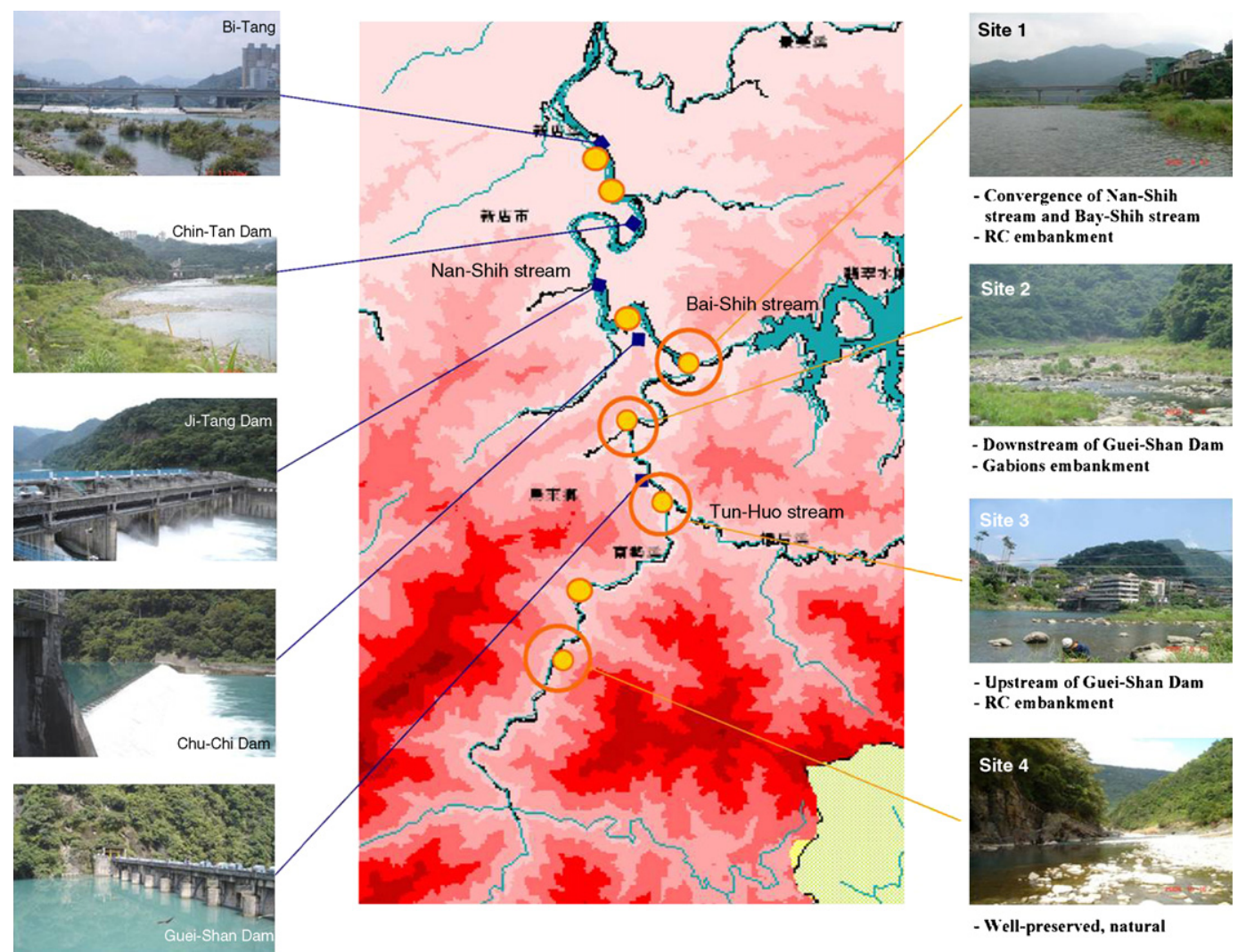

Fig. 2. Study area and sampling sites. Pictures of the artificial structures along Nan-Shih stream are shown as left side, while those of the representative sites are shown at right. Each site picture is shown with brief qualitative description below. 
physicochemical water quality, habitat parameters, and analysis of fish, benthic macroinvertebrates, and algae assemblages.

Water samples were analyzed for turbidity, dissolved oxygen, $\mathrm{pH}$, total phosphorus, and conductivity. Physical characterization included documentation of general land use, qualitative description of stream condition, summary of the riparian vegetation features, and measurements of instream parameters that included width, depth, flow, and substrate.

Fishes were collected by electrofisher $(8 \mathrm{~A} / 12 \mathrm{~V})$. The collections were limited $100 \mathrm{~m}$ at one side per sampling site. Collected fish were held in aerated buckets for identification, enumeration, and fish length measurements. Species that could not be identified in the field were preserved with $10 \%$ formalin and stored until laboratory identifications could be made. Remaining fish were returned to the stream after all collections were completed.

Benthic macroinvertebrate assemblages were sampled initiated at the downstream boundary of each site and proceeded upstream utilizing Suber net sampler within the $100 \mathrm{~m}$ reaches by collecting three jabs. Samples were preserved in $10 \%$ formalin for identification. Each organism was identified to family level.

Algae were collected from cobbles or boulders randomly sorted from each site. A tooth brush was used to remove diatom films from an area of ca. $100 \mathrm{~cm}^{2}$ on cobbles or boulders. After dissolving and filtering, specimens are preserved in a 3-5\% formalin solution for subsequent laboratory identification.

The integration of structural and functional characteristics of community assemblages allowed for the evaluation of instream responses to stressors and impairments as detected by species diversity metrics. Assessment of fish, benthic macroinvertebrates, and algae communities provided insight into the relative condition of the receiving stream.

\subsection{Indicators}

\subsubsection{Index of Biotic Integrity (IBI)}

Fish are good indicators of long-term effects and broad habitat conditions because they are relatively long-lived and mobile (Karr et al., 1986). Fish assemblage structure is reflective of integrated environmental health. Karr's IBI was used to assess the fish community assemblage (Karr, 1981, 1991; Karr et al., 1986). The IBI originally was designed to evaluate the quality of small midwestern streams in the U.S. The index scores 12 metrics in 3 categories species richness and composition, trophic composition, and fish abundance and condition - and compares with those expected in the least human disturbance. IBI has then been modified for use in many regions and in different ecosystems (U.S. EPA, 1999). Although designed for midwestern streams in the U.S., the options provided for selecting alternate fish species most representative of different stream systems. This allowed for environmental variability among different stream systems.

For the Nan-Shih stream, five metrics in the species richness and composition category were used to evaluate the extent to which the sample area supports reduced species richness and altered species composition. These include three taxon-specific metrics, i.e. suckers, darters, and sunfish, representing groups that consume benthic invertebrates as their primary food, one assessing the presence of species intolerant of human activities, and one assessing total species richness. Three metrics in the second category were used to evaluate the trophic composition of the fish community to assess the energy base and trophic dynamics of the resident biota. The proportion of omnivores increases and the proportion of insectivorous cyprinids decreases in degraded systems. In the category of fish abundance and condition, two metrics were chosen to evaluate population density and fish condition in Nan-Shih stream. The total number of individuals in the sample is an important parameter for evaluation because disturbed areas often have reduced fish abundances. This attribute is based on catch per unit sampling effort. The final attribute evaluates the frequency of hybridization. Each attribute reflects the quality of components of the fish community that respond to variation in different aspects of the aquatic system.

In order to allow for endemic fish assemblages, nine metrics described above were selected to better represent the stream system based on resident fish species found. Attributes of each species found in Nan-Shih stream were labeled before calculating the IBI. For instance, Acrossocheilus formosanus and Candidia barbata are found special in Taiwan which were both identified as omnivorous, darters, but 
Table 1

Metrics used to assess biological integrity of fish communities based on Index of Biotic Integrity (IBI) (after Karr, 1981, 1991; Karr et al., 1986)

\begin{tabular}{|c|c|c|c|}
\hline \multirow[t]{2}{*}{ Metrics } & \multicolumn{3}{|c|}{ Scoring criteria } \\
\hline & 5 & 3 & 1 \\
\hline \multicolumn{4}{|l|}{ Species richness and composition } \\
\hline 1. Total number of fish species & $\geqq 10$ & $4-9$ & $0-3$ \\
\hline 2. Number of darter species & $\geqq 3$ & $1-2$ & 0 \\
\hline 3. Number of sunfish species & $\geqq 2$ & 1 & 0 \\
\hline 4. Number of sucker species & $\geqq 2$ & 1 & 0 \\
\hline 5. Number of intolerant species & $\geqq 3$ & $1-2$ & 0 \\
\hline \multicolumn{4}{|l|}{ Trophic composition } \\
\hline $\begin{array}{l}\text { 6. Percent of individuals as } \\
\text { omnivores }\end{array}$ & $<60$ & $60-80$ & $>80$ \\
\hline $\begin{array}{l}\text { 7. Percent of individuals as } \\
\text { insectivorous }\end{array}$ & $>45$ & $20-45$ & $<20$ \\
\hline \multicolumn{4}{|l|}{ Fish abundance and condition } \\
\hline $\begin{array}{l}\text { 8. Number of individuals } \\
\text { in sample }\end{array}$ & $\geqq 101$ & $51-100$ & $0-50$ \\
\hline $\begin{array}{l}\text { 9. Number of hybrids or } \\
\text { exotics species }\end{array}$ & 0 & 1 & $\geqq 2$ \\
\hline
\end{tabular}

Ratings of 5, 3, and 1 are assigned to each metric according to whether its value approximates, deviates somewhat from, or deviates strongly from the value expected at a comparable site that is relatively undisturbed.

moderate intolerant and intolerant, respectively. Scoring criteria used for fish IBI determinations and its corresponding grade levels are presented in Tables 1 and 2. The final value of modified-IBI is summed by the nine items in Table 1 .

\subsubsection{Family-level Biotic Index}

The FBI (Hilsenhoff, 1988) aquatic insects Hilsenhoff index (Family-level Biotic Index) is evaluated by the Benthic macroinvertebrates samplings. Benthic macro-invertebrate integrate the effects of middle-term environmental variations. Most species have a complex life cycle of approximately 1 year or more. Its assemblages are made up of species

Table 2

Total Index of Biological Integrity (IBI) scores, integrity levels (modified from Karr, 1981, 1991; Karr et al., 1986)

\begin{tabular}{llll}
\hline Level & Biological condition category & Score range & Grade \\
\hline 1 & Non-impaired & $35-45$ & $\mathrm{~A}$ \\
2 & Slightly impaired & $23-34$ & $\mathrm{~B}$ \\
3 & Moderately impaired & $15-22$ & $\mathrm{C}$ \\
4 & Severely impaired & $0-14$ & $\mathrm{D}$ \\
\hline
\end{tabular}

Table 3

Family-level Biotic Index (FBI) values and levels

\begin{tabular}{lll}
\hline Level & Values & Grade \\
\hline Excellent & $0.00-3.75$ & $\mathrm{~A}$ \\
Very good & $3.76-4.25$ & $\mathrm{~B}$ \\
Good & $4.26-5.00$ & $\mathrm{C}$ \\
Fair & $5.01-5.75$ & $\mathrm{D}$ \\
Fairly poor & $5.76-6.50$ & $\mathrm{E}$ \\
Poor & $6.51-7.25$ & $\mathrm{~F}$ \\
Very poor & $7.26-10.00$ & $\mathrm{G}$ \\
\hline
\end{tabular}

that constitute a broad range of trophic levels and pollution tolerances, thus providing strong information for interpreting cumulative effects. Scoring criteria used for FBI determinations and its corresponding grade levels is presented in Table 3.

\subsubsection{Genus Index (GI index)}

Aquatic algae generally have rapid reproduction rates and very short life cycles, making them valuable indicators of short-term impacts. As primary producers, algae are most directly affected by physical and chemical factors. Algal assemblages are sensitive to some pollutants which may not visibly affect other aquatic assemblages. Genus Index (Wu, 1999; Wu and Kow, 2002), the ratio of abundance of Achnanthes, Cocconeis, and Cymbella to that of Cyclotella, Melosira, and Nitzschia, was thus used to analyze. The use of GI has the advantage that only identification to generic level is required, while the majority of conventional indices require identification to species. The relationship between the score and level is shown in Table 4.

\subsubsection{Index of Stream Condition}

ISC was developed in 1995 and then applied in Australia and other regions (Ladson et al., 1999) as an integrated measure of the state of a stream. The ISC is based on an assessment of five components of streams.

Table 4

Generic Index (GI) scores and levels

\begin{tabular}{lll}
\hline GI & Score range & Grade \\
\hline Mildly polluted & $>30$ & A \\
Slightly polluted & $30>$ GI $>11$ & B \\
Gently polluted & $11>$ GI $>1.5$ & C \\
Moderately polluted & $1.5>$ GI $>0.3$ & D \\
Severely polluted & GI $<0.3$ & E \\
\hline
\end{tabular}


Each of these components (a sub-index) is given a score based on the assessment of a number of indicators. ISC has been applied in Da-Kuo stream in Taiwan to check the effect of engineering. However, the necessity of modifying the ISC for reasonable use in Taiwan was proposed (Chou and Huang, 2003). Considering the environment of Nan-Shih stream and its different characteristics from other regions, modified sub-indices were applied in this study to calculate ISC.

The modification and development included reviewing previous assessment methods, and consulting with experts with knowledge of hydrology, geomorphology, aquatic ecology, riparian vegetation and function, water quality, and river management policy and practice. Results from the trials were discussed with Water Resources Agency (WRA) to make it more reliable.

Seventeen indicators in the modified-ISC were used to quantify aspects of stream condition. Related indicators made up each sub-index, i.e. hydrology, physical form, streamside zone, water quality, and aquatic life. The indicators determined the actual measurements that are required and these measurements are the basis of the indicator ratings. Indicator ratings were based on the difference between the current condition of a stream and a defined reference condition, i.e. site 4 in this study. The indicators in physical form and water quality were kept the same as the original ISC, while those in hydrology, streamside zone, and aquatic life were modified.
Human influences have altered the hydrology of Nan-Shih stream. At present, appropriate goals for the hydrology sub-index are to identify streams with significant hydrologic change and to indicate where detailed investigations should be considered. Since most of the dams along Nan-Shih stream were built in the early $30 \mathrm{~s}$, when no good flow data is available, 'impact of artificial structure' was used as the indicator to evaluate the extent that flow has been altered by dams, hydroelectric stations, etc. The rating is highest when no structures are found, and lowest when the number of the structures is more than three. With the concept of river continuum, a negative influence is anticipated if no ecological baseflow is taken into account when operating the artificial structures. Considering the minimum amount of flow discharge to maintain the aquatic life is an important issue especially in a place with highly variable rainfall conditions as in Taiwan (Wang et al., 2000; Chou and Huang, 2003). Therefore, the indicator of baseflow requirement is added in the hydrology sub-index to rate this aspect. Because of the degree of diversity in a river and flexibility of most aquatic organisms, there is probably no such sharp cut-off or single minimum flow. The "baseflow requirement" indicator used in the ISC is a way to examine if the concept of minimum flow is taken into account when operating the artificial structures, which usually just consider the human needs.

The streamside zone is the land and vegetation abutting streams. It is the link between streams and the

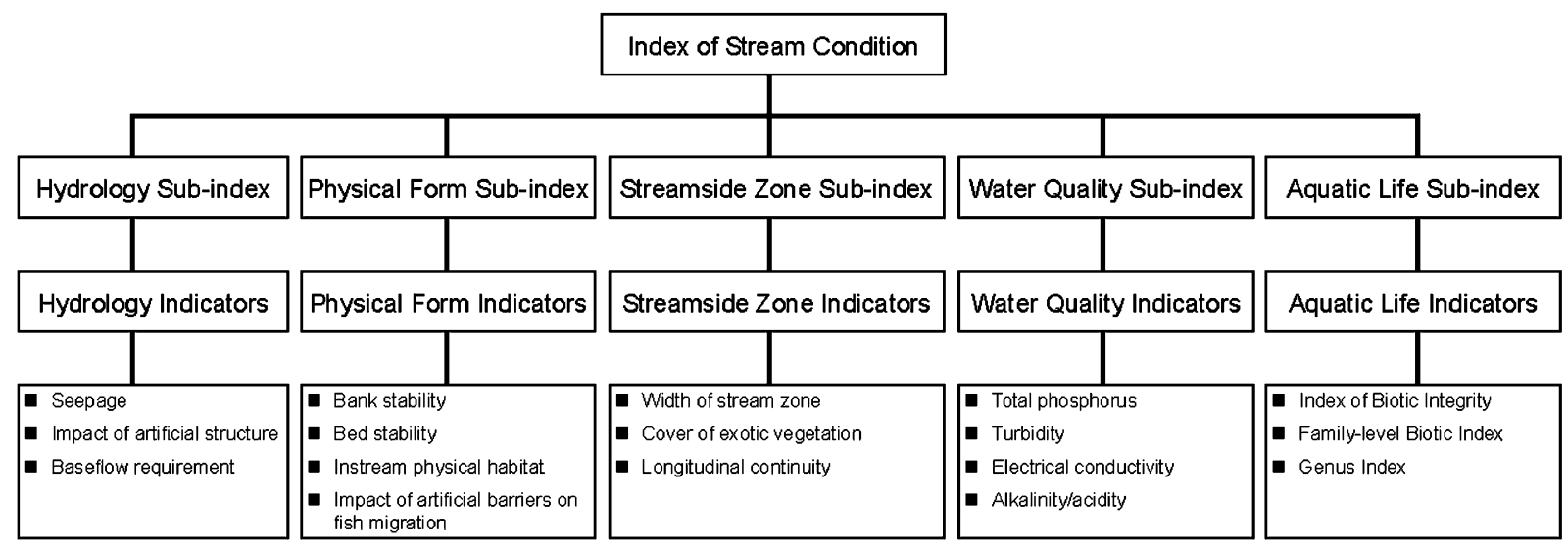

Fig. 3. Modified indicators under five sub-indices (i.e. hydrology, physical form, streamside zone, water quality, and aquatic life) used to assess the integrated measure of environmental condition based on the Index of Stream Condition (ISC). The maximum of each sub-index is 10. 
Table 5

Measurements and evaluation of the Index of Stream Condition (ISC)

\begin{tabular}{lll}
\hline ISC scores & Evaluation & \\
\hline $45-50$ & Excellent & A \\
$35-44$ & Good & B \\
$25-34$ & Marginal & C \\
$15-24$ & Poor & D \\
$<14$ & Very poor & E \\
\hline
\end{tabular}

surrounding catchment. Five indicators were selected for the Streamside Zone Sub-index with an upland reach in the original ISC, while two of them, i.e. structural intactness and regeneration of indigenous woody vegetation, were excluded in the evaluation of Nan-Shih stream in Taiwan. Since the understanding of the characteristics of the streamside zone were covered by the chosen indicators, extra efforts and cost of collecting the information of the remaining ones, which are too detailed and not appropriate to report the condition of the streamside zone, were neglected.

In the evaluation of aquatic life, the biotic components with different life spans which respond differently to certain stressors were used as the input to understand the ecosystem. Based on the field survey and the calculation above, IBI, FBI, and GI obtained were used as the input to the aquatic life sub-index. The overall ISC score is the sum of sub-index scores and is between 0 and 50, the higher scores indicating better condition. Fig. 3 summarizes the basis for each of these sub-indices and the chosen indicators. ISC scores and its corresponding grade are shown in Table 5.

\section{Results}

Results of water quality measurements from NanShih stream are given in Table 6. Measurements of water depth and the average composition of the substrates for Nan-Shih stream are presented in Figs. 4 and 5. Since site 3 is located directly upstream of the reservoir, water is relatively deep. Therefore, the water-depth of the right-side is not available.

As for the ecological survey, 20 fish species including 5 hybrids or exotics species (Carassius cuvieri, Cyprinus carpio, Tilapia zillii, Orechromis niloticus, and Plecoglossus altivelis), 8 orders, 23 benthic macroinvertebrates families, and 548,779 individuals of algae which are identified to 48 genuses were found. The results are shown in Table 7.

IBI values at these four sites are shown in Table 8 . From the result, only site 4 was considered slightly

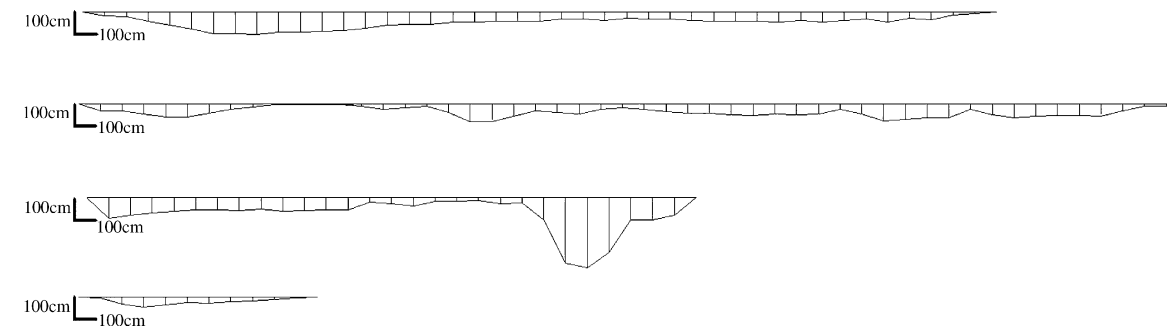

Fig. 4. Water depth measurements. Since site 3 is located directly upstream of the reservoir, water is relatively deep. Therefore, the water-depth of the right-side is not available.

Table 6

Summary of physic and chemical variables of water at sites (st1-st4) along Nan-Shih stream

\begin{tabular}{|c|c|c|c|c|c|}
\hline Items & st1 & st2 & st3 & st4 & Average \\
\hline Turbidity (NTU) & 18.01 & 6.66 & 14.29 & 7.61 & 11.64 \\
\hline $\mathrm{pH}$ & 7.90 & 8.14 & 7.52 & 7.61 & 7.79 \\
\hline Electrical conductivity $(\mu \mathrm{s} / \mathrm{cm})$ & 124.33 & 133.67 & 186.33 & 123.00 & 141.83 \\
\hline DO (mg/l) & 8.79 & 9.98 & 9.10 & 8.73 & 9.15 \\
\hline $\mathrm{TP}\left(10^{-2} \mathrm{mg} / \mathrm{l}\right)$ & 3.00 & 3.03 & 3.47 & 3.07 & 3.14 \\
\hline
\end{tabular}




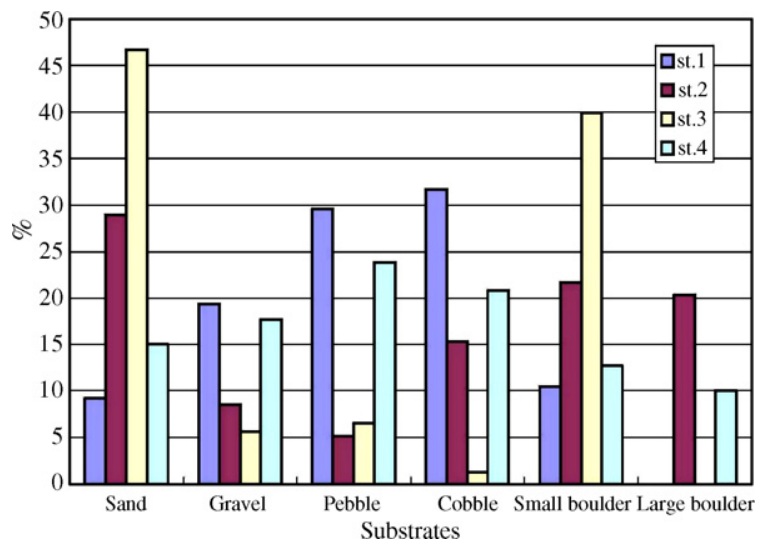

Fig. 5. Substrate measurements.

impaired since this site is located upstream and wellpreserved while the other three sites are moderately impaired. These results were attributed to the existence of the structures of the dams along the stream blocking the fish passages. FBI scores for sites 1,2 , and 4 were in the 'excellent' range, with scores of 3.4, 3.3, and 3.1. At site 3 of Nan-Shih stream scored 4.1 , which was in the 'very good' range. The results are shown in Table 8. GI values are 2.67, 20.83, 19.91, and 25.75 at these four sites separately shown in Table 8 . Site 1 is gently polluted, while the other three sites are slightly polluted.

The hydrology sub-index score of ISC was the lowest of any sub-index, which indicates impact of artificial structure and baseflow lack affecting flow significantly. With the physical form sub-index, the impact of artificial barriers on fish migration obtained
Table 8

Values of Index of Biotic Integrity (IBI), Family-level Biotic Index (FBI), and Generic Index (GI) at different sites during the time of this study

\begin{tabular}{llllll}
\hline Time & Index & st1 & st2 & st3 & st4 \\
\hline June & IBI & 17 & 21 & 17 & 25 \\
& FBI & 4.6 & 2.89 & 4.75 & 2.85 \\
& GI & 3.7 & 53 & 39.5 & 74.4 \\
August & IBI & 17 & 19 & 15 & 27 \\
& FBI & 3.57 & 2.83 & 3.33 & 3 \\
& GI & - & 8.85 & - & 2.08 \\
October & IBI & 25 & 23 & 15 & 25 \\
& FBI & 2.12 & 3.92 & 4.32 & 3.28 \\
& GI & 1.64 & 0.63 & 0.32 & 0.76 \\
December & IBI & 23 & 23 & 15 & 25 \\
& FBI & 3.36 & 3.57 & 4 & 3.25 \\
& GI & 2.67 & 20.83 & 19.91 & 25.74 \\
Average & IBI & 20.5 & 21.5 & 15.5 & 25.5 \\
& Level & C & C & C & B \\
& FBI & 3.41 & 3.30 & 4.10 & 3.10 \\
& Level & A & A & B & A \\
& GI & 2.00 & 20.83 & 14.93 & 25.75 \\
& Level & C & B & B & B \\
\hline
\end{tabular}

a low rating for the reach because of the structure blockage. High ratings were obtained for bank and bed stability. The streamside zone sub-index scored 9.53 . Both width of streamside zone and longitudinal continuity obtained high ratings. The water quality sub-index scored 9.4, which indicates the good water quality. Values of aquatic life sub-indices were obtained based on the IBI, FBI, and GI, suggesting

Table 7

Percentage of taxa occurred in Nan-Shih stream during the time of this study

\begin{tabular}{|c|c|c|c|c|c|}
\hline \multicolumn{2}{|l|}{ Fish } & \multicolumn{2}{|c|}{ Benthic macroinvertebrate } & \multicolumn{2}{|l|}{ Algae } \\
\hline Name & $\%$ & Name & $\%$ & Name & $\%$ \\
\hline Zacco platypus & 25 & Leptophlebiidae & 38.7 & Cymbella sp. 1 & 29 \\
\hline Acrossocheilus paradoxus & 24 & Heptageniidae & 15.7 & Gomphonema sp. 1 & 19 \\
\hline Crossostoma lacustre & 14 & Baetidae & 11.6 & Navicula sp. 1 & 11 \\
\hline Zacco pachycephalus & 10 & Chironomidae & 6.7 & Fragilaria sp. 1 & 8 \\
\hline Rhinogobius candidianus & 9 & Psephenidae & 4.7 & Fragilaria sp. 2 & 8 \\
\hline Hemimyzon formosanus & 5 & Hydropsychidae & 3.4 & Navicula sp. 3 & 5 \\
\hline Scaphesthes barbatulus & 3 & Perlidae & 2.8 & Gomphonema sp. 2 & 4 \\
\hline \multirow[t]{3}{*}{ Others } & 10 & Potamanthidae & 2.4 & Nitzschia sp. 1 & 4 \\
\hline & & Stenopsychidae & 2.4 & Others & 12 \\
\hline & & Others & 11.6 & & \\
\hline
\end{tabular}




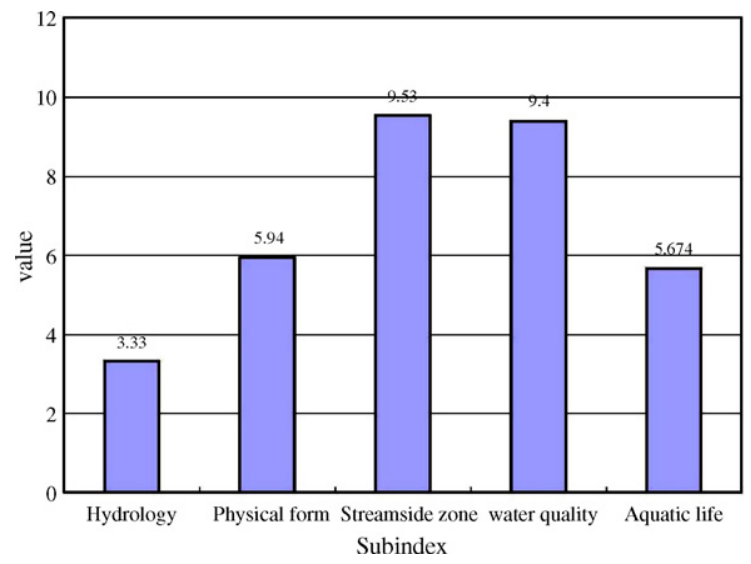

Fig. 6. Index of Stream Condition (ISC) scores for the study area. The hydrology sub-index score of ISC was the lowest of any subindex, which indicates impact of artificial structure and baseflow lack affecting flow significantly. The streamside zone sub-index scored 9.53. Both width of streamside zone and longitudinal continuity obtained high ratings. Values of aquatic life sub-indices were obtained based on the IBI, FBI, and GI, suggesting that Nan-Shih stream's overall aquatic biota state. As a whole, ISC value is 33.89 evaluated as marginal $\mathrm{C}$ level.

that Nan-Shih stream's overall aquatic biota state. As a whole, ISC value is 33.89 evaluated as marginal $\mathrm{C}$ level. The scores of each sub-index of ISC are shown in Fig. 6.

\section{Discussion and conclusions}

Human impacts on the biological integrity of water resources are complex and cumulative (Karr, 1981). Karr (1981) states that human actions jeopardize the biological integrity of water resources by altering one or more of five principal factors-physical habitat, seasonal flow of water, the food base of the system, interactions within the stream biota, and chemical quality of the water. These factors which can be addressed in environmental management require a measurement of ecosystem health. Biological assessment addresses ecosystem health and cumulative impacts by concentrating on population and community level. U.S. EPA advises incorporating more than one assemblage into biocriteria programs whenever practical. Surveying multiple assemblages provides a more complete assessment of biological condition since the various assemblages respond differently to certain stressors and restoration activities.

In the present study, evaluation has been made on the current state of Nan-Shih stream. The combination use of fish, benthic macroinvertebrates, and algae together with their corresponding indices, IBI, FBI, and GI, as a monitoring tool found to be well suited for quantitative assessments of community structure for this study. It permitted determinations of severity of impacts caused by structural modifications due to human activities. Streams are not just conduits for supplying water for human needs; they must also support other biological and botanical species. ISC has been developed as a tool to aid the management of waterways. Key stream condition indicators have been selected and refined. The results could now be provided to guide river managers to select and evaluate corresponding strategies, assist with priority setting and adaptive management, and judge the long-term restoration programs. Further use of these indicators in Taiwan can define the status of a resource and measure progress towards goals of attempts to improve the ecological properties of river systems.

This study was also undertaken to make recommendations for improvements in environmental restoration requirements. There is clear evidence that habitat alteration is a primary cause of degraded aquatic resources (U.S. EPA, 1997). Habitat degradation occurs as a result of hydrological flow modification, alteration of the system's energy base, or direct impact on the physical habitat structure. Preservation of an ecosystem's natural physical habitat is a fundamental requirement in maintaining diverse, functional aquatic communities in surface water (Rankin, 1995). The major problems degrading the environment is the longitudinal discontinuity resulting from dams and power stations, which cause siltation, damage of natural flow, and obstruct fish migration. The success of any restoration measure will depend both on the abiotic conditions - which may be repaired - and the species assemblage. The success of many restoration projects is limited because species are not present any more in the system or cannot reach the restored and now suitable sites.

The suggested measures of habitat rehabilitation and river habitat improvement could be divided into two categories, structural and non-structural methods. The structural method is setting up fishway facilities to 
create fish migration. The nonstructural methods are by means of releasing minimum flow and compensation for the ecological deficiency by releasing manmade captured species upstream of dams (Wang et al., 2000). More emphasis and maintenance on replacement of vegetative cover and riparian bank vegetation also would improve habitat by stabilizing stream banks and minimizing erosion problems. Channelization should be held to a minimum to preserve as much natural habitat as possible (e.g. fallen trees, root systems, etc.) (David and Wesley, 2005). Besides, from the long-term point of view, to minimize the impact on current geomorphology, sedimentation, and stability, the passageway towards generators could be considered to be closed down in order to make the flow natural (USDA, 2001).

In conclusion, our data suggest that fish collected from a stream impacted by hydraulic structures had signs of impairment at multiple levels of biological organization. We believe that investigations of habitat and biological effects should be continued and a larger sample of stream sites would strengthen the results that were found in this study.

\section{Acknowledgements}

The authors would like to thank Water Resources Agency and NSC-92-2211-E-267-004 for financial support. The authors also thank C.H. Lin and W.L. Lin for the identification of aquatic insects and algae. The authors of this work benefited greatly from discussions with Mr. S.S. Shih and Mr. A.M. Borghuis.

\section{References}

Cairns Jr., J., Mount, D.I., 1990. Aquat. Toxicol. Environ. Sci. Technol. 24, 154-161.

Cairns Jr., J., van der Schalie, W.H., 1980. Review paper: biological monitoring: Part I. Early warning systems. Water Res. 14, 1179_ 1196.

Chou, C.M., Huang, S.M., 2003. The evaluation process of ecological engineering method by Index of Stream Condition. J. Chin. Soil Water Conserv. 34 (1), 25-39.

Chu, T.J., 2005. The Assessment of ecological status after the stream repair by ecoengineering in the Hofangi Stream of Taipei County. J. Taiwan Conservancy 53 (3), 90-101 (in Chinese, with English abstract).
David, J.P., Wesley, J.B., 2005. Effectiveness of stream restoration following highway reconstruction projects on two freshwater streams in Kentucky. Ecol. Eng. 25, 73-84.

Hsu, C.B., Yang, P.S., 1997. Study on the assessment of water quality with biological indicators of aquatic insects in the Keelung river. Chin. J. Entomol. 17, 152-162 (in Chinese, with English abstract).

Hilsenhoff, W.L., 1988. Rapid field assessment of organic pollution with a Family-level Biotic Index. J. N. Am. Benthol. Soc. 7, 6568.

Hoffman, D.J., Rattner, B.A., Burton Jr., G.A., Cairns Jr., J., 1995. Quantifying and measuring ecotoxicological effects. In: Hoffman, D.J., Burton, G.A., Cairns, Jr., J., Rattner, B.A. (Eds.), Handbook of Ecotoxicology. Lewis Publishers, Boca Raton, FL, pp. 1-10.

Karr, J.R., 1981. Assessment of biotic integrity using fish communities. Fisheries 6, 21-26.

Karr, J.R., Fausch, K.D., Angermeier, P.L., Yant, P.R., Schlosser, I.J., 1986. Assessing biological integrity in running water: a method and its rationale. Ill. Nat. Hist. Surv. Spec. Publ. 5, 1-28.

Karr, J.R., 1991. Biological integrity: a long-neglected aspect of water resource management. Ecol. Appl. 1 (1), 66-84.

La Point, T.W., 1995. Signs and measures of ecotoxicity in the aquatic environment. In: Hoffman, D.J., Burton, G.A., Cairns, Jr., J., Rattner, B.A. (Eds.), Handbook of Ecotoxicology. Lewis Publishers, Boca Raton, FL, pp. 13-34.

Ladson, A.R., White, L.J., Doolan, J.A., Finlayson, B.L., Hart, B.T., Lake, P.S., Tilleard, J.W., 1999. Development and testing of an Index of Stream Condition for waterway management in Australia. Fresh Water Biol. 41 (2), 453-468.

Lai, S.D., Ho, S.T., Yu, K.C., 1994. Study on the correlation between the biota and ecological factor of San-Yeh-Kong river. J. Technol. 9 (1), 103-114 (in Chinese, with English abstract).

Liang, S.H., Bruce, W., Menzel, 1997. A new method to establish scoring criteria of the Index of Biotic Integrity. Zool. Stud. 36 (3), 240-250.

National Science Council, 1992. Restoration of Aquatic Ecosystems: Science, Technology, and Public Policy. National Academy Press, Washington, DC, pp. 8-15.

Rankin, E.T., 1995. Habitat Indices in Water Resource Quality Assessments. Biological Assessment and Criteria: Tools for Water Resource Planning and Decision Making. Lewis Publisher, Boca Raton, FL, pp. 181-208.

Shen, H.W., Chen, S.C., 1998. Goals and indicators of river basin studies based on ecological consideration. J. Chin. Soil Water Conserv. 29 (2), 165-173.

USDA, 2001. Stream Corridor Restoration: Principles, Processes, and Practices. The Federal Interagency Stream Restoration Working Group (FISRWG).

U.S. EPA, 1997. Guidelines for Preparation of the Comprehensive State Water Quality Assessments (305b reports). U.S. Environmental Protection Agency, Office of Water, Washington, DC, EPA 841-B-97-002A.

U.S. EPA, 1999. In: Barbour, M.T., Gerritsen, J., Snyder, B.D., Stribling, J.B. (Eds.), Rapid Bioassessment Protocols for Use in Wadeable Streams and Rivers: Periphyton, Benthic, Macroinvertebrates and Fish. second ed. U.S. Environmental Protec- 
tion Agency, Washington, DC, EPA 841-B-99-002 (Chapters 1 and 10 ).

Wang, C.M., Lin, W.Y., Ko, S.Y., Chuang, C.K., Tu, Y.Y., Tsai, H.H., 2000. Phase study of ecology and fish cinservation around LiChi Stream of Cho-Shui River System. Monthly J. Taipower's Eng. 91-111 (in Chinese, with English abstract).
Wu, J.T., 1999. A Generic Index of diatom assemblages as bioindicator of pollution in the Keelung river of Taiwan. Hydrobiologia 397, 79-87.

Wu, J.T., Kow, L.T., 2002. Applicability of a Generic Index for diatom assemblages to monitor pollution in the tropical river Tsanwun, Taiwan. J. Appl. Phycol. 14, 63-69. 